This is an author produced version of a paper published in Social Science and MedicineThis paper has been peer-reviewed but does not include the final publisher proof-corrections or journal pagination.

Citation for the published paper:

Ali SM, Merlo J, Rosvall M, Lithman T, Lindstrom M.

"Social capital, the miniaturisation of community, traditionalism and first time acute myocardial infarction: A prospective cohort study in southern Sweden

Social Science and Medicine, 2006, Issue: June 22.

http://dx.doi.org/10.1016/j.socscimed.2006.04.007

Access to the published version may require journal subscription.

Published with permission from: Elsevier 


\section{Social capital, the miniaturisation of community, traditionalism and first time acute myocardial infarction (AMI): A prospective cohort study in southern Sweden}

Sadiq Mohammad Ali ${ }^{1}$, Juan Merlo ${ }^{2}$, Maria Rosvall ${ }^{1}$, Thor Lithman ${ }^{2}$, Martin Lindström ${ }^{1}$

1 Department of Health Sciences

Malmö University Hospital

Lund University

S-205 02 Malmö

Sweden

Tel. +46-040-333003

Fax. +46-040-336215

E-mail: martin.lindstrom@smi.mas.lu.se

Word count (Abstract): 294

Word count (Text): 5,421
2 Department of Clinical Sciences

Malmö University Hospital

Lund University

S-205 02 Malmö

Sweden 


\section{Abstract}

To investigate the impact of social participation, trust and the combinations of social participation and trust on the incidence of first time acute myocardial infarction in the population of Scania, southern Sweden. This longitudinal study is based on the crosssectional 2000 public-health survey in Scania with a 59\% participation rate and 13,604 participants, and prospective morbidity/mortality data collected for three years (January 2000-December 2002). The study cohort was followed prospectively to examine first-ever acute myocardial infarction (AMI). Hazard rate ratios for first time AMI in the social participation, trust and social participation/trust combinations were calculated in a Cox regression model with adjustments for age, sex, education, economic stress, daily smoking, leisure time physical activity, BMI, and self reported health. The prevalence of low social participation was 32.8\% among men and 31.5\% among women. The prevalence of low trust was $40.0 \%$ among men and $44.2 \%$ among women. The three-year first time acute myocardial infarction rate was significantly higher among people with higher age, low education, daily smoking, poor self reported health (among men), low social participation, and the combinations of low social participation/high trust and low social participation/low trust. The results showed that low social participation but not trust was significantly associated with first time acute myocardial infarction after adjustment for age and sex. The positive association between low social participation and myocardial infarction remained significant after further adjustments for education, economic stress, daily smoking, physical activity and BMI, and became not significant only after additional adjustment for self reported health, HRR 1.3 (0.9-2.0). High trust in combination with low social participation as well as low social capital (low trust/low social participation) were significantly associated with acute myocardial infarction, but after multiple adjustments only the low social participation/high trust category remained significant, HRR 1.6 (1.0-2.6).

Keywords: Acute myocardial infarction, social capital, social participation, trust, miniaturization of community, morbidity, mortality. 


\section{Introduction}

Myocardial infarction is the leading cause of death in Sweden as well as in most industrialized nations throughout the world. During the years 1987-2002 about 502,000 persons with acute myocardial infarction (AMI) were registered in Sweden, and the number of incident cases was more than 640,000 . Almost 350,000 of these 502,000 persons died during the period, of which 255,000 with AMI as a cause of death (National Board on Health and Welfare 2005). The most important and classical risk factors for AMI as well as for coronary heart disease (CHD) and other cardiovascular diseases include smoking, high blood cholesterol and hypertension, followed by other somewhat less important but still potent risk factors such as obesity, low levels of physical activity, diabetes mellitus type II, socioeconomic status and psychosocial factors (27 $7^{\text {th }}$ Bethesda Conference 1996). Self reported global health is a strong predictor of mortality and morbidity (Lopez 2004).

The association between socioeconomic status (SES) (measured as either education, income or occupational status), cardiovascular risk factors, and coronary heart disease (CHD)/acute myocardial infarction (AMI) is well known. This association has been demonstrated in many studies in many different countries in individual (Bucher and Ragland 1995; Ellaway et al. 1997; Kunst et al. 1999; Hemingway et al. 2000; Salomaa et al. 2000; Wamala 2001) and multilevel (Kleinschmidt et al.; Reijneveld 1998; LeClere et al. 1998) analyses.

In recent years the concept of social capital has been introduced in the public health literature, and the relationship between social capital and health has been intensively studied during the past decade. Social capital is regarded as an asset for the individual and collective production of well-being (Putnam 2000). Kawachi et al. found in an ecological study that lower levels of social trust were associated with higher rates of most major causes of death, including coronary heart disease, cerebrovascular disease, unintentional injury, and infant mortality (Kawachi et al. 1997). Studies concerning the relationships between social capital and health also include such different topics as for instance mortality rates in individual level (Lochner et al. 2003) and ecological studies (Skrabski et al. 2003), self rated health in individual level (Veenstra 2000) and multilevel studies (Putnam 2000; Lindström 2004a; Subramanian et al. 2002), mental 
health (Drukker et al 2003), smoking and smoking cessation (Lindström et al. 2002), cannabis smoking (Lindström 2004b), leisure time physical activity (Lindström et al. 2001; Lindström et al. 2003), as well as alcohol consumption (Weitzman et al. 2000) analysed at the individual level of analysis. Social capital has also been discussed as a tool for exploring community level influences on HIV infection (Campbell et al. 2002).

The theoretical suggestions and empirical findings concerning social capital and health have not remained unquestioned. Authors who criticize the proposition that social capital influences health, the so called neo-materialists, claim that the academic study of social capital and health obscures the relationship between political, administrative and economic determinants, and health. The neo-materialists emphasize the importance of active governments and public welfare programs (Navarro 2004). They also criticize the social capital literature for creating an artificial dichotomy between material and psychosocial factors which according to these authors are determined by socioeconomic conditions which they have in common, and for reintroducing the psychosocial stress theory which according to these authors has proved to accumulate scientific knowledge poorly (Muntaner 2004). This critique against the social capital and health literature is a rationale for studying a hypothetical direct psychosocial pathway between social capital and acute myocardial infarction.

Social capital is also a multidimensional concept not easily defined. Macinko and Starfield have defined four different levels for the analysis of social capital: the macro (countries, regions), the meso (neighbourhoods), the micro (social network/social participation of the individual) and the psychological/attitudinal (trust) levels (Macinko and Starfield 2001). In our study only the micro (social participation of the individual) and the psychological (trust) levels are analysed.

Social capital has been hypothesized to be associated with health by four causal pathways including psychosocial mechanisms, the norms and values influencing health related behaviours, access to health care, and crime, particularly violent crime (Kawachi et al. 1999). In our study, adjustments are made for daily smoking and leisure time physical activity, two health related behaviours which are important risk 
factors for cardiovascular disease, as well as for the cardiovascular risk factor BMI (National Public Health Report 2005). The adjustments for daily smoking, leisure time physical activity and BMI in the multiple regression models in this study implies that we investigate the possibility of a direct psychosocial pathway between social capital (social participation and trust) and acute myocardial infarction (see Figure 1). Still, these adjustments may account for lack in association between aspects of social capital and acute myocardial infarction in this paper, because of the inclusion of these health related behaviour and BMI variables in the model. In a recent Swedish study, Sundquist et al. demonstrated an increased risk of CHD among persons with low social capital measured as low social participation after adjustments for a number of variables including smoking (Sundquist et al. 2004). In this study we not only adjust also for physical activity and BMI, but we also analyse the effects of the four possible combinations of social participation and trust on first ever acute myocardial infarction.

Social capital has mostly been operationalised as social participation/social networks and/or trust in empirical studies. Social participation and trust have been suggested to represent different aspects of social capital (Putnam 1993a). Social participation and trust are often hypothesized to mutually enhance and strengthen each other. High levels of social participation are expected to increase generalized trust, and high levels of generalized trust are expected to lead to high social participation in different activities, organizations, associations and formal and informal social networks (Putnam 1993b). However, the positive relationship between social participation and trust may not be particularly strong. Putnam suggests that the quality of social participation has changed to some extent from participation in ideologically and programmatically broad organizations and associations to much more ideologically narrowly defined single issue movements and social participation on the internet. The relationship between social capital and the internet is a new and evolving issue. Some obstacles on the internet to building social capital like the digital divide might be overcome by public policy, but other obstacles such as anonymity and single strandedness may be harder to address (Putnam 2000). These new forms of social participation might be one explanation why the level of generalized trust in other people has been declining in the USA over the past decades, although the level of social participation remains high. This process may result in an increase in the 
prevalence of people with the combination of high level of social participation and low trust. This decreased radius of trust in such social networks has been defined by Francis Fukuyama as "the miniaturization of community“ (Fukuyama 1999). This phenomenon makes the understanding of social participation, trust, their combination and their mutual relationship, and the relationship with health and health related behaviours more complex but also more fruitful. It increases the emphasis on the evaluation of the quality of social participation and trust rather than the quantity. It also theoretically suggests that there might be an independent association between the miniaturisation of community, mortality, morbidity and health related behaviours. In fact, recent data from Scania (Skåne) in southern Sweden demonstrate the lack of association between social participation and trust. In a survey conducted in 2000, social participation decreases dramatically with increasing age among both men and women. In contrast, generalized trust in other people increases dramatically with increasing age in both sexes (Lindström 2004a). The correlation coefficient between social participation and trust is only 0.12 in this study, which is a finding strongly in support of Fukuyama. Individual level studies have also indicated that the miniaturisation of community combination of high social participation and low trust is significantly and positively associated with intermittent smoking (Lindström 2003), poor psychological health (Lindström 2004a), high consumption of illegal alcohol (Lindström 2005a), high alcohol consumption (Lindström 2005b), high level of dissatisfaction with treatment in primary health care (Lindström and Axén 2004), high prevalence of having experienced cannabis smoking (Lindström 2004b), and a higher propensity of anxiolytic-hypnotic drug use (Johnell et al. 2005) in southern Sweden. The Scania (Skåne) region in the southernmost part of Sweden is a region with incidence and mortality rates in 1999-2001 which can be described as being very close to the average for the whole of Sweden for both men and women (National Public Health Report 2005). The findings suggest that the four possible combinations of social participation and trust may also be associated with morbidity and mortality in first ever acute myocardial infarction (AMI). The main hypothesis of this study is that people with low social capital, i.e. the combination of both low social participation and low trust, have a higher incidence of first ever acute myocardial infarction than people with high social capital, i.e. high social participation and high trust. The combinations of high social participation/low trust, i.e. the miniaturization of community, and low social participation/high trust which has be named 
traditionalism in a previous paper (Lindström 2003), might a priori be expected to increase the incidence of first ever acute myocardial infarction. However, it is not known if high social participation or high trust buffer the possible detrimental effect of low social capital. It is also possible that the "miniaturization” category has a higher risk of AMI for the reasons given above.

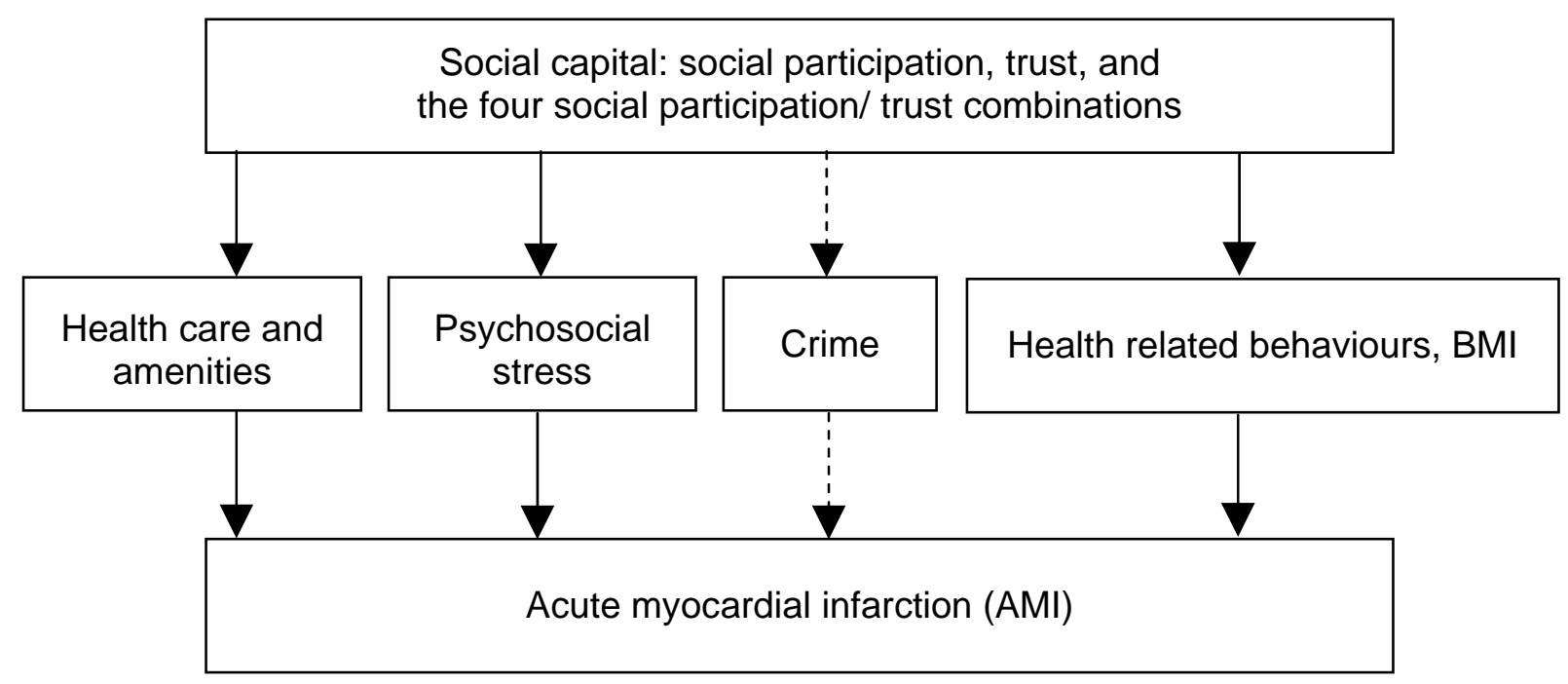

Figure 1. Social capital, social participation, trust and their combinations and acute myocardial infarction. A model of causal pathways.

\section{Aim}

The aim of this study is to investigate the impact of social participation, trust and the four combinations of social participation and trust on first-ever acute myocardial infarction in the population in Scania, southern Sweden, January 2000-December 2002. 


\section{Material and methods}

\section{Study population}

The public-health survey in Scania in southern Sweden is a cross sectional study based on self reported information from a postal questionnaire survey of a total of 24,922 randomly selected persons born between 1919 and 1981 that received the postal questionnaire over the period November 1999 to February 2000. A total of 13,715 persons answered the questionnaire (111 incomplete). This represents $59 \%$ of the population sample. The population of the study shows similar prevalences of age, sex, marital status and educational level as well as health care consumption as the general population of Scania when comparisons with general register data are conducted (Carlsson et al. 2005). The random sample was weighted by age, sex, and geographic area to account for the non-proportional stratified sampling of the survey and ensure that correct estimations of prevalence (\%) for the entire Scania region are given. The weights do not adjust for non response. In this study we calculated incidence rates and hazard rate ratios of first time myocardial infarction. Since 196 men and 86 women of the participants in the survey had had one or more myocardial infarctions prior to January 2000, these persons were excluded from this study. Consequently, the number of persons at risk was 13,322, 6,006 men and 7,316 women.

\section{Definitions}

\section{Dependent variables}

\section{First time acute myocardial infarction}

Cases of first time acute myocardial infarctions $\left(10^{\text {th }}\right.$ version ICD code $I 20$ for morbidity and ICD I20-I25 for mortality) during a three year time period (January 2000-December 2002) following the 1999/2000 baseline survey investigation were retrieved from the national register of causes of death and inpatient register in Sweden at the Centre for Epidemiology- National Board of Health and Welfare. Both fatal and non-fatal cases were included in this study. A personal identification number, 
assigned to each person in Sweden, is recorded in all registers and was used for record linkages between the health survey in Scania 2000 investigation, the In Care register, and the Swedish Cause-of-Death register.

All participants were informed on the purposes of the survey and consented to link the questionnaire information with the health care registers. The Regional Ethical Committee in Lund approved this research.

\section{Independent variables}

Age is divided into the age intervals under 35, 35-44, 45-54, and 55-64, and more than 64 years.

The analyses in tables 1 and 2 are stratified by sex. The analyses in table 3 are adjusted for sex for reasons of statistical power.

Education is divided by length of education into 9 years or less, 10-12 years, and 13 or more years of education.

Economic stress is categorized by the answer to the question "How many times during the past year did you not have money enough to afford the food or the clothes you and your family need?” There are four alternative answers: (1) “Every month”, (2) “Approximately six months a year”, (3) “Very occasionally”, and (4) “Never”.

Daily smoking is classified as either daily smoker or not daily smoker at baseline.

Low leisure time physical activity is assessed with a question with four alternative answers. The first alternative is a completely sedentary leisure time physical activity status. The second alternative involves at least four hours of light leisure time physical activity (walking, bicycling etc.) per week. The third alternative comprises regular physical exercise and training, and the fourth hard and regular training at the élite level. In this study, leisure time physical activity is dichotomized into active in physical activities (the three latter alternatives) and physical inactivity (the first alternative). 
Body Mass Index (BMI). Obesity is defined as BMI 30.0 or more, overweight as BMI 25.0-29.9, and normal weight as BMI -24.9. BMI is computed from the self reported estimations of weight $(\mathrm{kg})$ and height $(\mathrm{m})$ in the questionnaire. The proportion of persons with underweight (BMI 18.5 or less) is very small in the population of this study ( $<1 \%$ among men and $<2.5 \%$ among women).

Self reported health is assessed by an item consisting of seven alternatives. The first alternative entails a completely bad health (bad, couldn't be worse). The second alternative is a straightforward "bad" and the third "somewhat bad". The fourth alternative is neutral, followed by “somewhat good”, “good” and “good, couldn’t be better”. The self reported health variable is dichotomized into good and bad health with the three first alternatives as "bad" health and the four other alternatives as "good” health.

Social participation (during the past year) describes how actively the person takes part in the activities of formal and informal groups in society. Respondents are asked whether in the previous 12 months they have been involved in any of the following activities: study circle/course at workplace, other study circle/course, union meeting, meeting of other organisations, theatre/cinema, arts exhibitions, church, sports event, letter to the editor of a newspaper/journal, demonstration, night club/entertainment, large gathering of relatives, and private party. It is measured as an index consisting of 13 items and dichotomised. If three alternatives or less are indicated, the social participation of that individual is classified as low. The social participation index variable in this study has been used to measure social participation in Sweden since the 1960s and the 1970s, and is a valid and reliable measure (National Central Bureau of Statistics 1980).

Trust is a self-reported variable that reflects the person's perception of generalized trust in other people. It was assessed by the item 'Generally, You can trust other people' that contains four alternative answers: 'Do not agree at all', 'Do not agree', 'Agree', and 'Completely agree'. It was dichotomized with the two first alternatives as low trust and the two latter alternatives as high trust. 
The combination of social participation and trust results in four alternatives: high social participation/high trust (high social capital), high social participation/low trust (“the miniaturization of community”), low social participation/high trust, (traditionalism) and low social participation/low trust (low social capital).

\section{Statistics}

Prevalences (\%) of demographic, socioeconomic, health related behaviour, self reported health, social participation, trust, and the social participation/trust combinations are calculated, stratified by sex. Significance tests (t-tests) for sex differences are conducted (table 1).Three-year first-ever AMI incidence rates and number of events are calculated according to demographic, socioeconomic, health related behaviour, self reported health, social participation, trust, and the social participation/trust combinations, stratified by sex. Tests for trends in myocardial infarction are calculated for age, education, economic stress, daily smoking, leisure time physical activity, BMI, self reported health, social participation, trust and the four social participation/trust combinations in univariate logistic regression models (table 2). Adjusted hazard rate ratios (HRR, 95\% CI) of first time acute myocardial infarction according to social participation, trust and the social participation/trust combinations are calculated in Cox regression survival models adjusted for age, sex, education, economic stress, daily smoking, low leisure-time physical activity, BMI, and self reported health (Table 3). The prevalence estimates presented are weighted in table 1, and the weights are also used in the calculations in tables 2 and 3 . The statistical analysis is performed using the SPSS software package. 


\section{Results}

The age distribution is very similar among men and women with $\mathrm{p}=0.18$ for sex difference (table 1). Respondents with high education constitute $24.9 \%$ of the male population and $27.7 \%$ of the female population $(\mathrm{p}<0.001$ for sex differences in educational level). The prevalences of the economic stress alternatives significantly differ between men and women, $\mathrm{p}<0.001$. The prevalences of daily smoking significantly differ between men (17.2\%) and women (19.8\%) with $\mathrm{p}=0.002$ for sex difference. A $15.3 \%$ of the men and $15.0 \%$ of the women have low levels of leisure time physical activity ( $\mathrm{p}=0.17$ for sex difference). In contrast, there is a significant sex difference in BMI with $42.5 \%$ of all men but only $27.9 \%$ of all women being overweight (BMI 25.0-29.9) ( $\mathrm{p}<0.001$ for sex difference). The prevalence of bad self reported health is $10.6 \%$ among men and $13.0 \%$ among women $(\mathrm{p}<0.001$ for sex difference). A $32.8 \%$ of all men and $31.5 \%$ of all women have low social participation ( $p=0.51$ for sex difference). The corresponding prevalences for low trust are $40.0 \%$ and $44.2 \%$, respectively ( $<<0.001$ for sex difference). The four social participation/trust combinations are distributed with somewhat more women in the high social participation/low trust category and somewhat more men in the low social participation/high trust category ( $\mathrm{p}=0.03$ for sex difference).

Table 2 shows the three year first ever AMI incidence rates by demographic, socioeconomic, health related behaviours, self reported health, and social capital variables. The differences in incidence rates between men and women are, as expected, very substantial. Higher age ( $\mathrm{p}<0.001$ for trend in acute myocardial infarction in the age categories for both men and women), low education ( $\mathrm{p}<0.001$ for both men and women), being a daily smoker ( $<<0.001$ for both men and women), having bad self reported health (significant trend for men, $p=0.003$, but not for women, $\mathrm{p}=0.60$ ), having low social participation ( $\mathrm{p}<0.001$ for both men and women), having low social participation/high trust (traditionalists), and having low social participation/low trust (low social capital) ( $\mathrm{p}<0.001$ for both men and women) are characteristics significantly associated with high incidence rates of first time acute myocardial infarction. The heading of table 2 shows that the numbers of first ever myocardial infarctions were 101 among men (55 non-fatal and 46 fatal) and 52 among women (38 non-fatal and 14 fatal). 
Table 3 shows that the hazard rate ratio of first time acute myocardial infarction is 2.1 (1.5-3.0) in the low social participation compared to the high social participation reference category after adjustments for age and sex. The HRR for low social participation remains significantly higher after multivariate adjustments for age, sex, education, economic stress, daily smoking, leisure time physical activity and BMI in the Cox regression survival analysis model, 1.5 (1.0-2.3). The HRR for low social participation becomes not significant only after the additional introduction of baseline self reported health in the model, $1.3(0.9-2.0)$. The HRR:s for the low trust compared to the high trust category remain not significant throughout the adjusted analyses, 0.9 (0.6-1.3) after adjustment for only age and sex, and 0.8 (0.5-1.2) after adjustments for all confounders. The HRR:s for the miniaturization of community category (high social participation/low trust) remain not significant and very close to 1 throughout the analyses compared to the high social capital (high social participation/high trust) category, $1.0(0.6-2.0)$ in the first model and $1.0(0.5-1.8)$ in the final model. In contrast, the traditionalist (low social participation/high trust) category retains significantly higher HRR:s throughout the multivariate analyses compared to the high social capital reference group, 2.4 (1.6-3.8) in the age- and sex-adjusted model and $1.6(1.0-2.6)$ in the final model. The low social capital (low social participation/low trust) category has a significantly higher hazard than the high social capital reference category only in the initial age- and sex-adjusted Cox regression model, 1.8 (1.1-3.0). 


\section{Discussion}

This study shows that low social participation is significantly associated with incidence of first ever acute myocardial infarction, while no such significant association between trust and incidence of first ever acute myocardial infarction is observed. The significant positive association between low social participation and first ever acute myocardial infarction only becomes not significant after the final adjustment for self reported health. The results also show that the three-year first-ever AMI hazard rate ratio is significantly higher in the group with the combination of low social participation and high trust (traditionalists) compared to the high social capital (high social participation/high trust) category even after multivariate adjustments for age, sex, education, economic stress, daily smoking, leisure time physical activity, body mass index (BMI) and self reported health. This somewhat surprising result sharply contrasts the result concerning the miniaturization of community (high social participation/low trust) category, in which no significant differences in hazard rate ratio is observed compared to the high social capital reference category. The hypothesized significantly higher hazard rate ratio for the low social capital (low social participation/low trust) category only remained in the initial demographic ageand sex-adjusted model, and became not significant already in the next model adjusted for age, sex, education and economic stress. The adjustments for tobacco smoking, leisure time physical activity and BMI may account for some of the lack in association between aspects of social capital and acute myocardial infarction in this paper, because of the inclusion of these health related behaviour and BMI variables in the model.

The participation rate is 59\%. The population of the study shows similar prevalences of age, sex, marital status and educational level as well as health care consumption as the general population of Scania when comparisons with general register data are conducted (Carlsson et al. 2005). The sampling method is easier in Sweden than in many other countries, because of the Swedish population register. A personal identification number, assigned to each person in Sweden, is recorded in all registers and was used for record linkages between the health survey in Scania 2000 investigation, the In Care register, and the Swedish Cause-of-Death register. All inhabitants in Scania included in the baseline study are eligible for linking and almost 
all eligible link with the In Care and Cause-of-Death registers. A small number of individuals might have left the country without notifying the authorities, but this most plausibly will not have affected the results of this study. Consequently, the risk of selection bias is rather small in this study.

The Swedish In Care and the Cause-of-Death registers are of internationally high standard concerning validity and reliability, particularly when it comes to CHD and AMI. The risk of non-differential misclassification is probably of minor importance in this study, because non-differential misclassification tends to attenuate true differences, and this study shows significant differences between the social participation/trust combination categories in the initial stages of the analyses. Self reported health status is a valid indicator of health and chronic diseases; it has been stated that self reported health is a valid indicator of health in middle aged populations (Miilunpalo et al. 1997), strongly related to chronic diseases and physicians ratings of health status (Wilson and Kaplan 1995; Goldstein et al. 1984), and cohort mortality in the USA (Idler at al. 1990; Grant et al. 1995; Schoenfeld et al. 1994), and Sweden (Sundquist and Johansson 1997). Self reported health is thus a valid indicator of health status and predictor of mortality, and its inclusion in the analyses means that we have taken the health status at baseline into account in this prospective longitudinal cohort study. Furthermore, we have also censored all participants in the baseline investigation that had had a first time acute myocardial infarction before January 2000.

The social participation item has been used and is known as a valid and reliable item in Sweden since the 1960s and 1970s (National Central Bureau of Statistics 1980). However, it only measures whether social participation in the thirteen different activities occurred at one single occasion during the past year or not. It does not take into account either the intensity (number of times during the year of participation in a certain activity) or the extent of involvement (being the chairman of an organization or just passively participating in one or a number of meetings). The trust item concerns self reported trust, which is not possible to validate. However, the prevalence of low trust in this study has a good correspondence with other studies in Sweden (Rothstein 1996). 
The overlap between the sub-item "sports event" in the social participation item and the leisure time physical activity item is probably low, because the "sports event" subitem is designed to measure activities such as being a spectator of a soccer game, while the leisure time physical activity item measures the extent of physical activity (indirectly in terms of energy expenditure).

Although very central and essential, social participation and trust are only two aspects of social capital. Many studies now use multi-dimensional measures of social capital, including measures of reciprocity, social harmony, sense of belonging and civic action in addition to social participation and trust (Harpham and Grant 2002). Only social participation and trust were included in this study because they were the only social capital items availably in the data set. Still, they are also the two items needed to analyze the miniaturization of community.

Confounding was controlled for by adjusting for age, sex, education, economic stress, daily smoking, leisure time physical activity, BMI and self reported health, and by censoring individuals with previous events of first time acute myocardial infarction.

The longitudinal prospective cohort study design may be considered an important strength in this study.

A potential weakness of this study is residual confounding which may be due to the fact that the two classical cardiovascular risk factors high plasma cholesterol and hypertension have not been assessed in this data material. Still, we have adjusted for BMI which may be regarded as an indirect measure of the metabolic syndrome in a general Western population (Björntorp 1997).

The somewhat higher three-year incidence of first time acute myocardial infarction among male respondents with no economic stress is solely an effect of age, younger people experiencing more economic stress than older.

The results are based on the analyses of both fatal and non-fatal cases of acute myocardial infarction over a three-year period. However, separate analyses (one including only men and one including both men and women) of the associations 
between low social participation and low trust, and fatal acute myocardial infarction not presented in the tables yield the same results as in this study, i.e. a significantly positive association between low social participation and acute myocardial infarction in all models except the final model, and no significant association between low trust and acute myocardial infarction throughout the analyses.

The results demonstrating a significantly higher hazard rate ratio of first ever acute myocardial infarction in the traditionalist (low social participation/high trust) category compared to the high social capital (high/high) category may theoretically be due to the possibility that there might be a concentration of traditionalists in the oldest age group at the highest risk of myocardial infarction. However, although the traditionalists are overrepresented in the higher age groups, there is still a very substantial proportion of traditionalists even in the younger age groups (Lindström 2004a). Second, the adjustment for age as a possible confounder lowered the hazard rate ratio somewhat, but it still remained highly significant. Third, we have conducted separate analyses stratified for age in the 18-64 and 65-80 years age intervals, respectively. These analyses, not presented in the tables, yield the same patterns of higher hazard rate ratios in the traditionalist category as in table 3 in both the age strata.

This longitudinal prospective cohort study shows that low social participation is significantly associated with first ever acute myocardial infarction (AMI). In contrast, low trust is not significantly associated with AMI. There has been a debate in social epidemiology whether social participation/social networks or trust are the core of social capital. Some theorists have suggested that the "ties" and norms binding individuals within constituent elements of large organizations or linking them across a variety of institutional and formal and informal associational realms (Granovetter 1973). Other authors regard social capital as a "moral resource" such as "trust" (Fukuyama 1995). The results of this study clearly suggest that it is the social participation and social network component of social capital, and not the trust component, that has a crucial connection with coronary health, at least in the setting in southern Sweden. Social participation is one of the most important components of social capital and it represents an important channel of communication in the community. There are different causal pathways by which social participation might 
influence the risk of having acute myocardial infarction. First, social participation may indirectly affect health and myocardial infarction through influencing health related behaviours such as particularly tobacco smoking, physical activity, and dietary patterns (see introduction). This pathway entails the influence of social participation on health related behaviours by the promotion of the more rapid diffusion of health information (Rogers 1983), the encouragement of healthy norms such as e.g. physical activity and healthy dietary habits, and the social control over deviant health related behaviours (Putnam 2000). Second, a direct causal pathway by which social participation influences health is by influencing psychosocial stress, self efficacy, self esteem, coping effectiveness and sense of well being. Psychosocial and environmental stress may in the long run enhance life style behaviours such as tobacco smoking (Wills et al. 2002; Shiffman et al. 1996), low physical activity (Schnor et al. 2005) and dietary habits. Furthermore, studies show that neighbourhood social capital may influence the health of individuals by providing affective support and by being the source of self-esteem and mutual respect (Wilkinson 1996). Social support may also influence health through enhanced self efficacy in coping with abortion (Major et al. 1990), smoking cessation (Gulliver et al. 1995), depression (McFarlane et al. 1995), and the maintenance of self efficacy (MacAvay et al. 1996). There might also be a physiological pathway, in which low social participation and isolation may influence health and coronary heart disease, e.g. acute myocardial infarction, by increasing psychological stress which in turn activates the hypothalamic-pituitaryadrenocortical (HPA) axis by the release of corticotropic-releasing factor (CRF) from neuronal cell bodies of the paraventricular nucleus (Dallman 1993), which ultimately cause the release of cortisol (McEwen et al. 1993; Koob et al. 1993). Increasing the production of cortisol, stress causes various sympathetic changes, including increased blood pressure, heart rate (HR), and catecholamine production (Cacioppo 1994; Christensen 1994) and, ultimately, heart disease.

The combination of low social participation and high trust is significantly associated with increased risk of first ever acute myocardial infarction even after adjustments for different confounders. The causal pathways connecting social capital and acute myocardial infarction may include both the direct psychosocial pathway and the pathway including intermediate health related norms and attitudes already discussed and described in connection with Figure 1 above. The traditionalist category might be 
exposed to an increased risk of psychosocial and biological stress (see references above) incurred by the increased vulnerability of having high trust and low social participation/poor social networks in a low trust society (at least compared with previous conditions in Sweden) in which almost $50 \%$ of the population have low trust. The risk of being imposed upon or fooled seems high in this group, even compared with the low social capital group. This result may have important international health implications, given the fact that the prevalences of high trust in for instance the international Human Values and Beliefs surveys by Inglehart et al. varied in the early 1990s between 7\% in Brazil, 10\% in Turkey and 16\% in Romania to substantially more than 50\% in Sweden, Norway, Finland, Denmark and the Netherlands (Inglehart et al. 1998). In contrast, the participants in the miniaturization of community category may be protected by the high social participation and social networks in which they take part. It may also be possible that the result for the traditionalist category is only a consequence of the fact that low trust has no significant association with acute myocardial infarction, although this explanation would still not account for the fact that the low social participation category does not remain significantly associated with acute myocardial infarction throughout the analyses. Contextual factors such as the influence of different neighbourhoods on different individuals, e.g. different exposure to different forms of psychosocial stress in different neighbourhoods, might also explain these findings. Such factors have not been taken into account in this study in which only individual level social participation and trust have been analysed. The investigation of contextual influences would call for multilevel analyses. At this stage it is only possible to hypothesize about these findings. It is evident that the findings call for further studies.

Although recent studies have indicated an association between the miniaturisation of community combination of high social participation and low trust with a number of health related behaviours and other health related outcomes (Lindström 2003; Lindström 2004a; Lindström 2004b; Lindström 2005a; Lindström 2005b; Lindström and Axén 2004), the miniaturisation of community was not associated with increased risk of acute myocardial infarction in this study. However, the main finding in these studies is the significant association between the miniaturisation of community and psychological health, and poor psychological health in the population is known to be a 
chronic condition associated with a reduction in Daily Active Living Year's (DALY's) rather than myocardial infarction (National Public Health Report 2005).

The main finding that low social participation but not low trust is associated with the incidence of first ever acute myocardial infarction has implications for public health policy. It seems that empowerment, i.e. the ability of people to gain understanding and control over personal, social, economic and political forces in order to improve their own life situation, is important (Ife 1995). This would imply a public health policy which promotes the participation of citizens in formal and informal networks of society (Baum et al. 2000).

\section{Conclusion}

The results show that low social participation, but not low trust is significantly associated with first ever acute myocardial infarction. The study also shows that low social participation in combination with high trust is positively associated with first ever acute myocardial infarction.

\section{Acknowledgements}

This study was supported by grants from the ALF Government Grant Dnr M:B $1003 / 2004$. 


\section{References}

Baum, F., Bush, R.A., Modra, C.C., Murray, C.J., Cox, E.M., Alexander, K.M., and Potter, R.C: (2000). Epidemiology of participation: an Australian community study. Journal of Epidemiology and Community Health, 54, 414-423.

$27^{\text {th }}$ Bethesda Conference: "Matching the intensity of risk factor management with the hazard for coronary disease events”. Journal of the American College of Cardiology 1996; 27: 957-963.

Björntorp, P. (1997). Behaviour and the metabolic disease. International Journal of Behavioural Medicine, 3, 285-302.

Bucher, H.C., Ragland, D.R. (1995). Socioeconomic indicators and mortality from coronary heart disease and cancer: A 22-year follow-up of middle-aged men. American Journal of Public Health, 85(9), 1331-1236.

Cacioppo, J.T. (1994). Social neuroscience: autonomic, neuroendocrine, and immune response to stress. Psychophysiology, 31, 113-128.

Campbell, C., Williams, B., Gilgen, D. (2002). Is social capital a useful conceptual tool for exploring community level influences on HIV infection? An exploratory case study from South Africa. AIDS Care, 14(1), 41-54.

Carlsson, F., Merlo, J., Lindström, M., Östergren, P.O., Lithman, T. (2005). Representativity of a postal health questionnaire survey in Sweden, with special reference to ethnic differences in participation. Scandinavian Journal of Public Health, In press.

Christensen, N. (1994). Effect of psychosocial stress and age on plasma norepinephrine levels: a review. Psychosomatic Medicine, 56, 77-83.

Dallman, M. (1993). Stress update: adaptation of the hypothalamic-pituitary-adrenal axis to chronic stress. Trends in Endocrinological Metabolism, 4, 62-69. 
Drukker, M., Gunther, N., Feron, F.J., van Os, J. (2003). Social capital and mental health vs. objective measures of health in The Netherlands. British Journal of Psychiatry, 183, 174.

Ellaway, A., Anderson, A., MacIntyre, S., (1997). Does area of residence affect body size and shape? International Journal of Obesity, 21(4), 304-308.

Fukuyama, F. (1995). Trust. The social virtues and the creation of prosperity. New York, London, Toronto, Sydney, Tokyo, Singapore: The Free Press.

Fukuyama, F. (1999). The great disruption: human nature and the reconstitution of social order. London: Profile Books.

Goldstein, M.S., Siegel, J.M., Boyer, R. (1984). Predicting changes in perceived selfreported health status. American Journal of Public Health, 74, 611-14.

Granovetter, M. (1973). The strength of weak ties. American Journal of Sociology, 78, 1360-1380.

Grant, M.D., Piotrowski, Z.H., Chappell, R. (1995). Self-reported health and survival in the Longitudinal Study of Aging. 1984-1968. Journal of Clinical Epidemiology, 48, 375-87.

Gulliver, S.B., Hughes, J.R., Solomon, L.J., Dey, A.N. (1995). An investigation of self-efficacy, partner support and daily stresses as predictors of relapse to smoking in self-quitters. Addiction, 90(6), 767-72.

Harpham, T., Grant, E., Thomas, E. (2002). Measuring social capital within health surveys: key issues. Health Policy and Planning, 17(1), 106-11.

Hemingway, H., Shipley, M., Macfarlane, P., Marmot, M. (2000). Impact of socioeconomic status on coronary mortality in people with symptoms, 
electrocardiographic abnormalities, both or neither: The original Whitehall study 25 year follow up. Journal of Epidemiology and Community Health, 54(7), 510-516.

Idler, E.L., Angel, R.J. (1990). Self-rated health and mortality in NHANES-I

Epidemiologic Follow-up Study. American Journal of Public Health, 80, 446-52.

Ife, J. (1995). Community development. Creating community alternatives- vision, analysis and practice. Melbourne: Longman.

Inglehart, R., Basanez, M., Moreno, A. (1998). Human Values and Beliefs. A CrossCultural Sourcebook. Ann Arbor: The University of Michigan Press.

Johnell, K., Lindström, M., Melander, A., et al. (2005). Anxiolytic-hypnotic drug use associated with trust, social participation, and the miniaturization of community: A multilevel analysis. Social Science and Medicine In press (E-pub ahead of publishing).

Kawachi, I., Kennedy, B.P., Lochner, K., Prothrow-Stith, D. (1997). Social capital, income inequality, and mortality. American Journal of Public Health, 87, 1491-8.

Kawachi, I., Kennedy, B.P., Glass, R. (1999). Social capital and self-rated health: a contextual analysis. American Journal of Public Health, 89, 1187-1193.

Kleinschmidt, I., Hills, M., Elliott P. (1995). Smoking behaviour can be predicted by neighbourhood deprivation measures. Journal of Epidemiology and Community Health, 49 (Suppl. 2), S72-77.

Koob, G.F., Heinrichs, S.C., Pich, E.M., et al. (1993) The role of corticotropinreleasing factor in behavioral responses to stress. CIBA Found Symp 172. In: Chadwick DJ, Marsh S, Ackrill K (eds.) Corticotropin-releasing factor. Wiley, Chichester, pp 277-295. 
Kunst, A.E., Groenhof, F., Andersen O. et al. (1999). Occupational class and ischemic heart disease mortality in the United States and 11 European countries. American Journal of Public Health, 89(1), 47-53.

Leclere, F.B., Rogers, R.G., Peters K. (1998). Neighborhood social context and racial differences in women's heart disease mortality. Journal of Health and Social Behaviour, 39(2), 91-107.

Lindström, M. (2003). Social capital and the miniaturization of community among daily and intermittent smokers: A population-based study. Preventive Medicine, 36, 177-184.

Lindström M. (2004a). Social capital, the miniaturisation of community and selfreported global and psychological health. Social Science and Medicine, 59, 595-607.

Lindström, M. (2004b). Social capital, the miniaturization of community and cannabis smoking among young adults. European Journal of Public Health, 14, 204-208.

Lindström, M. (2005a). Social capital, the miniaturization of community and consumption of home made liquor and smuggled liquor during the past year: A population-based study. European Journal of Public Health (In press).

Lindström, M. (2005b). Social capital, the miniaturization of community and high alcohol consumption: A population-based study. Alcohol and Alcoholism, In press.

Lindström, M., Axén, E. (2004). Social capital, the miniaturization of community and assessment of patient satisfaction in primary healthcare: a population-based study. Scandinavian Journal of Public Health, 32(4), 243-9.

Lindström M, Hanson B.S, Ostergren P.O. (2001). Socioeconomic differences in leisure-time physical activity: The role of social participation and social capital in shaping health related behaviour. Social Science and Medicine, 52, 441-451. 
Lindström, M., Isacsson, S.O. (2002). Smoking cessation among daily smokers, aged 45-69 years: A longitudinal study in Malmö, Sweden. Addiction, 97, 205-215.

Lindström M, Moghaddassi M, Merlo J. (2003). Social capital and leisure time physical activity: a population based multilevel analysis in Malmo, Sweden. Journal of Epidemiology and Community Health, 57, 23-28.

Lochner, K.A., Kawachi, I., Brennan, R.T., Buka, S.L. (2003). Social capital and neighborhood mortality rates in Chicago. Social Science and Medicine, 56(8), 17971805.

Lopez, R. Income inequality and self-rated health in US metropolitan areas: a multilevel analysis. Social Science and Medicine 2004; 59 (12): 2409-2419.

Macinko, J., Starfield, B. (2001). The utility of social capital in research on health determinants. The Milbank Quarterly, 79(3), 387-427.

Major, B., Cozzarelli, C., Sciacchitano, A.M., et al. (1990). Perceived social support, self-efficacy, and adjustment to abortion. Journal of Personal and Social Psychology, 59, 452-63.

McAvay, G.J., Seeman, T.E., Rodin, J. (1996). A longitudinal study of change in domain-specific self-efficacy among older adults. Journal of Gerontology and Bulletin of Psychology Science Social Science, 51(5), 243-53.

McEwen, B.S., Stellar, E. (1993). Stress and the individual: mechanisms leading to disease. Archives of Internal Medicine, 153, 2093-2101.)

McFarlane, A.H., Bellissimo, A., Norman, G.R. (1995). The role of family and peers in social self-efficacy: links to depression in adolescence. American Journal of Orthopsychiatry, 65(3), 402-10.

Miilunpalo, S., Vuori, I., Oja, P., et al. (1997). Self-rated health status as a health measure: the predictive value of self-reported health status on the use of physician 
services and on mortality in the working-age population. Journal of Clinical Epidemiology, 50, 517-28.

Muntaner, C. (2004). Commentary: social capital, social class, and the slow progress of psychosocial epidemiology. International Journal of Epidemiology, 33, 674-80.

National Board on Health and Welfare. http://www.sos.se/epc/english/summary.htm. Stockholm: National Board on Health and Welfare, 2005.

National Central Buteau of Statistics (1980). Living conditions. Isolation and togetherness- An outlook on social participation 1976. Report no. 18. Stockholm: The National Central Bureau of Statistics, 1980.

National Public Health Report for Sweden 2005. (2005). Stockholm: National Board on Health and Welfare.

Navarro, V . (2004). Commentary: is social capital the solution or the problem? International Journal of Epidemiology, 33, 672-4.

Putnam, R.D. (1993a). The prosperous community: social capital and public life. American Prospect, 13, 35-42.

Putman, R.D. (1993b). Making democracy work. Civic traditions in modern Italy. Princeton: Princeton University Press.

Putman, R.D. (2000). Bowling alone: the collapse and revival of American community. New York, London: Simon and Schuster.

Reijneveld, S.A. (1998). The impact of individual and area characteristics on urban socioeconomic differences in health and smoking. International Journal of Epidemiology, 27(1), 33-40.

Rogers, E. (1983). Diffusion of innovations. New York: Free Press 
Rothstein, B. (1996). Sociala fällor och tillitens problem (Social traps and the problem of trust) in Holmberg, S., Weibull, L (eds.) Ett missnöjt folk? (A discontent people?) The SOM Investigation 1996. SOM-report nr. 18. Göteborg: The SOM Institute.

Salomaa, V., Niemela, M., Miettinen, H., et al. (2000). Relationship of socioeconomic status to the incidence and prehospital, 28-day, and 1-year mortality rates of acute coronary events in the FINMONICA myocardial infarction register study. Circulation, 101 (16), 1913-1918.

Shiffman, S., Hickcox, M., Paty, J.A., et al. (1996). Progression from a smoking lapse to relapse: prediction from abstinence violation effects, nicotine dependence, and lapse characteristics. Journal of Consulting Clinical Psychology, 64, 993-1002.

Schnohr, P., Kristensen, T.S., Prescott, E., Scharling, H. (2005). Stress and life dissatisfaction are inversely associated with jogging and other types of physical activity in leisure time--The Copenhagen City Heart Study. Scandinavian Journal of Medical Science in Sports, 15(2), 107-12.

Schoenfeld, D.E., Mamrose, L.C., Blazer, D.G., et al. (1994). Self-rated health and mortality in the high-functioning elderly- a closer look at healthy individuals: MacArthur Field Study of Successful Aging. Journal of Gerontology, 49: M109-15.

Skrabski, A., Kopp, M., Kawachi, I. (2003). Social capital in a changing society: Cross sectional associations with middle aged female and male mortality rates. Journal of Epidemiology and Community Health, 57:2, 114-119.

Subramanian, S.V., Kim, D.J., Kawachi, I. (2002). Social trust and self-rated health in US communities: A multilevel analysis. Journal of Urban Health, 79:4 (Suppl. 1); S21-S34.

Sundquist, J., Johansson, S.E. (1997). Self-reported poor health and low educational level predictors for mortality: a population-based follow-up of 39, 156 people in Sweden. Journal of Epidemiology and Community Health, 51, 35-40. 
Sundquist, K., Lindström, M., Malmström, M., et al. (2004). Social participation and coronary heart disease: a follow-up study of 6900 women and men in Sweden. Social Science and Medicine, 58; 615-622.

Wamala, S.P. (2001). Large social inequalities behind women's risk of coronary disease. Unskilled work and family strains are crucial factors. Läkartidningen, 98(3), $177-181$

Veenstra, G. (2000). Social capital, SES and health: An individual-level analysis. Social Science and Medicine, 50:5, 619-629.

Weitzman, E.R, Kawachi, I. (2000). Giving means receiving: The protective effect of social capital on binge drinking on college campuses. American Journal of Public Health, 90:2, 1936-1939.

Wills, T.A., Sandy, J.M., Yaeger, A.M. (2002). Stress and smoking in adolescence: a test of directional hypotheses. Health Psychology, 21, 122-130.

Wilkinson, R. G. (1996). Unhealthy societies: The afflictions of inequality. London: Routledge.

Wilson, I.B., Kaplan, S. (1995). Clinical practice and patients’ self-reported health status: how are the two related? Medical Care, 33 (Suppl.), S209-14. 
Table 1. Prevalence (\%) of demographic, socioeconomic, health related behaviour, self reported health, social participation, trust, and the social participation/trust combinations variables characteristics, and significance tests (t-tests) for sex differences for each of the variables. Men $(n=6006)$, women $(n=7316)$, and total $(n=13322)$. Population weight applied. The public health survey in Scania 2000.

Age

Under 35 years

35- 44 years

45-54 years

55-64 years

More than 65 years

(Missing)

\section{Education}

13-year

10-12 years

-9 years

(Missing)

Economic stress

Never

Occacionally

Every second month

Every month

(Missing)

Daily smoking

No

Yes

(Missing)

Low leisure time

physical activity

No

Yes

(Missing)

BMI

$-24.9$

25.0-29.9

30.0-

(Missing)

Self reported health

Good

Bad

(Missing)

Social participation

High

Low

(Missing)

Trust

High

Low

(Missing)

Combination

of social participation

trust

High /high

High /low

Low /trust

Low/ low

(Missing)

\section{Men}

16.9

20.2

18.3

19.3

(0)

24.9

42.4

32.7

(255)

72.5

18.4

4.2

4.9

(151)

82.8

17.2

(104)

84.7

15.3

(223)

47.2

42.5

10.3

(162)

89.4

10.6

(185)

67.2

32.8

(229)

60.0

40.0

(208)

43.6

24.1

16.8

15.5

(311)
Women

25.7

17.9

20.4

16.6

19.3

(0)

27.7

40.2

32.1

(395)

69.6

19.8

4.5

6.1

(254)

80.2

19.8

(129)

85.0

15.0

(338)

62.1

27.9

10.0

(329)

87.0

13.0

(322)

68.5

31.5

(287)

55.8

44.2

(291)

41.5

27.5

14.4

16.6

(433)
25.5

17.5

20.3

17.4

19.3

(0)

26.4

$\mathrm{p}<0.001 \quad 41.2$

32.4

(650)

70.9

19.2

4.4

5.5

(405)

$\mathrm{p}=0.002$

81.3

18.7

(233)

$\begin{array}{cc}\mathrm{p}=0.17 & 84.9 \\ & 15.1 \\ & (561)\end{array}$

55.3

34.6

10.1

(491)

88.1

11.9

(507)

67.9

32.1

(516)

57.7

42.3

(499) 
Table 2. Three-year acute myocardial infarction incidence according to demographic, socioeconomic, health related behaviour, BMI, self reported health, social participation, trust, and the social participation/trust combinations. Men ( $n=101$ first time myocardial infarctions, of which 55 surviving and 46 dead, 6006 men at risk at baseline) and women (n= 52 first time myocardial infarctions, of which 38 surviving and 14 dead, 7316 women at risk at baseline). Population weight applied. The public health survey in Scania 2000.

\begin{tabular}{|c|c|c|c|c|}
\hline & \multicolumn{2}{|c|}{ Men } & \multicolumn{2}{|c|}{ Women } \\
\hline & $\begin{array}{l}\text { Three year } \\
\text { incidence } \\
\text { rate }\end{array}$ & $\begin{array}{c}\mathrm{n} \\
\text { (cases) }\end{array}$ & $\begin{array}{l}\text { Three year } \\
\text { incidence } \\
\text { rate }\end{array}$ & $\begin{array}{c}\mathrm{N} \\
\text { (cases) }\end{array}$ \\
\hline Age & & & & \\
\hline Under 35 years & 0.000 & 0 & 0.000 & 0 \\
\hline 35- 44 years & 0.001 & 1 & 0.000 & 0 \\
\hline $45-54$ years & 0.007 & 9 & 0.007 & 11 \\
\hline 55-64 years & 0.021 & 23 & 0.007 & 8 \\
\hline $\begin{array}{l}\text { more than } 65 \text { years } \\
\text { (Missing) }\end{array}$ & 0.059 & $\begin{array}{l}68 \\
(0)\end{array}$ & 0.023 & $\begin{array}{l}33 \\
(0)\end{array}$ \\
\hline $\begin{array}{l}\text { Test for trend } \\
\text { Education }\end{array}$ & $\mathrm{p}<0.001$ & & $\mathrm{p}<0.001$ & \\
\hline 13-year & 0.008 & 12 & 0.002 & 3 \\
\hline $10-12$ years & 0.007 & 17 & 0.003 & 7 \\
\hline $\begin{array}{l}-9 \text { years } \\
\text { (Missing) }\end{array}$ & 0.032 & $\begin{array}{c}61 \\
(11)\end{array}$ & 0.015 & $\begin{array}{c}32 \\
(10)\end{array}$ \\
\hline $\begin{array}{l}\text { Test for trend } \\
\text { Economic stress }\end{array}$ & $\mathrm{p}<0.001$ & & $\mathrm{p}<0.001$ & \\
\hline Never & 0.018 & 78 & 0.007 & 32 \\
\hline Occasionally & 0.013 & 14 & 0.009 & 13 \\
\hline Every $2^{\text {nd }}$ month & 0.012 & 3 & - & - \\
\hline $\begin{array}{l}\text { Every month } \\
\text { (Missing) }\end{array}$ & 0.010 & $\begin{array}{l}3 \\
(3)\end{array}$ & 0.007 & $\begin{array}{c}3 \\
(4)\end{array}$ \\
\hline $\begin{array}{l}\text { Test for trend } \\
\text { Daily smoking }\end{array}$ & $\mathrm{p}=0.13$ & & $\mathrm{p}=0.92$ & \\
\hline No & 0.013 & 65 & 0.006 & 34 \\
\hline $\begin{array}{l}\text { Yes } \\
\text { (Missing) }\end{array}$ & 0.031 & $\begin{array}{l}31 \\
(5)\end{array}$ & 0.013 & $\begin{array}{l}18 \\
(0)\end{array}$ \\
\hline $\begin{array}{l}\text { Test for trend } \\
\text { Low leisure-time } \\
\text { physical activity }\end{array}$ & $\mathrm{p}<0.001$ & & $\mathrm{p}=0.009$ & \\
\hline No & 0.015 & 76 & 0.007 & 39 \\
\hline $\begin{array}{l}\text { Yes } \\
\text { (Missing) }\end{array}$ & 0.019 & $\begin{array}{l}17 \\
(8)\end{array}$ & 0.008 & $\begin{array}{c}8 \\
(5)\end{array}$ \\
\hline $\begin{array}{l}\text { Test for trend } \\
\text { BMI }\end{array}$ & $\mathrm{p}=0.42$ & & $p=0.69$ & \\
\hline-24.9 & 0.013 & 35 & 0.005 & 22 \\
\hline $25.0-29.9$ & 0.019 & 48 & 0.009 & 17 \\
\hline $\begin{array}{l}\text { 30.0- } \\
\text { (Missing) }\end{array}$ & 0.018 & $\begin{array}{l}11 \\
(7)\end{array}$ & 0.009 & 6 \\
\hline $\begin{array}{l}\text { Test for trend } \\
\text { Self reported } \\
\text { health }\end{array}$ & $\mathrm{p}=0.09$ & & $\mathrm{p}=0.10$ & \\
\hline good & 0.015 & 76 & 0.006 & 38 \\
\hline $\begin{array}{l}\text { bad } \\
\text { (Missing) }\end{array}$ & 0.031 & $\begin{array}{l}19 \\
(6)\end{array}$ & 0.008 & $\begin{array}{c}7 \\
(7)\end{array}$ \\
\hline $\begin{array}{l}\text { Test for trend } \\
\text { Social } \\
\text { participation }\end{array}$ & $\mathrm{p}=0.003$ & & $\mathrm{p}=0.60$ & \\
\hline High & 0.009 & 34 & 0.003 & 13 \\
\hline $\begin{array}{l}\text { Low } \\
\text { (Missing) }\end{array}$ & 0.032 & $\begin{array}{l}60 \\
(7)\end{array}$ & 0.014 & $\begin{array}{l}31 \\
(8)\end{array}$ \\
\hline Test for trend & $\mathrm{p}<0.001$ & & $\mathrm{p}<0.001$ & \\
\hline
\end{tabular}


Trust

$\begin{array}{lcccc}\text { High } & 0.019 & 66 & 0.007 & 26 \\ \begin{array}{l}\text { Low } \\ \text { (Missing) }\end{array} & 0.013 & 29 & 0.007 & 21 \\ \begin{array}{l}\text { Test for trend } \\ \text { Combination } \\ \text { of social } \\ \text { participation }\end{array} & \mathrm{p}=0.06 & (6) & & (5) \\ \text { trust } & & & \mathrm{p}=0.95 & \\ \begin{array}{l}\text { High/ high } \\ \text { High/ low }\end{array} & 0.010 & 25 & 0.002 & 6 \\ \begin{array}{l}\text { Low/ high } \\ \text { Low/ low } \\ \text { (Missing) }\end{array} & 0.007 & 9 & 0.003 & 6 \\ \text { Test for trend } & 0.039 & 37 & 0.017 & 17 \\ & 0.022 & 19 & 0.011 & 13 \\ & \mathrm{p}<0.001 & (11) & & (10)\end{array}$


Table 3. Adjusted hazard rate ratios (HRR, 95\% CI) of first time acute myocardial infarction according to social participation, trust and miniaturization of community. Men and women ( $N=153 / 13,322)$. Population weight applied. The public health survey in Scania 2000.

\section{$\begin{array}{llll}\operatorname{HRR}(95 \% \mathrm{CI})^{*} & \text { HRR }(95 \% \mathrm{CI})^{+} & \text {HRR }(95 \% \mathrm{CI})^{\varepsilon} & \operatorname{HRR}(95 \% \mathrm{CI})^{\$}\end{array}$}

\section{Social participation}

High

1.00

2.1 (1.5-3.0)

Low

Trust

High

Low

$0.9(0.6-1.3)$

$$
\begin{gathered}
1.00 \\
\mathbf{1 . 8}(\mathbf{1 . 2}-\mathbf{2 . 6})
\end{gathered}
$$

$$
1.00
$$

$0.9(0.6-1.3)$

$0.9(0.5-1.3)$

0.8 (0.5-1.2)

Combination

of social

participation/trust

High /high

$0.9(0.6-1.3)$

1.00

1.00

1.00

1.00

High /low

Low /high

$1.0(0.6-2.0)$

$2.4(1.6-3.8)$

$1.0(0.6-2.0)$

$1.0(0.5-1.8)$

$1.0(0.5-1.8)$

$1.8(1.1-3.0)$

$2.0(1.3-3.3)$

$1.7(1.1-2.9)$

$1.6(1.0-2.6)$

Low/low

* Adjusted for age and sex.

+ Adjusted for age, sex, education and economic stress.

$£$ Adjusted for age, sex, education, economic stress, leisure time physical activity, daily smoking, and BMI.

\$ Adjusted for age, sex, education, economic stress, leisure time physical activity, daily smoking, BMI and self reported health. 